\title{
A Prehistorical Evolutionary View of Diplomacy ${ }^{1}$
}

Iver B. Neumann

Museum of Cultural History, University of Oslo, i.b.neumann@khm.uio.no

Place Branding and Public Policy, 17 January 2018, Doi.org/

$10.1057 / \mathrm{s} 41254-017-0089-\mathrm{Z}$

\section{Abstract}

Extant discussions of diplomacy understood as a social institution either take the form of histories or genealogies. This chapter attempts to complement these discussions by understanding the emergence of diplomacy in terms of evolutions. Specifically, I draw on Eldredge and Gould's idea of punctuated equilibria or tipping points, understood as the culmination of long-term trends. Taking note of the importance of big game hunting as a precondition for human cooperation generally, I go on to identify five more tipping-points. These are classificatory kinship as a template for regular cooperation; regular and ritualized contacts between culturally similar smallscale polities; regular and ritualized contacts between culturally different large-scale polities; permanent bilateral diplomacy and permanent multilateral diplomacy. Inconclusion, I discuss what seems to be a trend on its way to become a new tippingpoint, namely that states increasingly hybridise their diplomacy by working with and through non-state actors.

Keywords: DIPLOMACY, EVOLUTION, KINSHIP, NON-STATE ACTORS, RELIGION 
We have a lively evolutionary debate about a number of international institutions, perhaps most notably war (e.g. Carman and Harding 1999; Fry 2007), but nothing on diplomacy. When the concept is used in extant literature, it is used pre-Darwin style to denote diplomacy as evolved not by the human species in general, but by specific states or by diplomacy itself (Nicolson 1963; Watson 1992; Hamilton and Langhorn 2011; Kurizaki 2011).

The perspective taken here is different. Diplomacy is seen as an emergent institution shaped by its social and material environment. Humanity shapes diplomacy, and diplomacy shapes humanity. The two are co-constitutive. The stress here is on how humanity evolves diplomacy. This is because one point of the exercise is to say something about how diplomacy is changing here and now, and in order to do that, it is optimal to focus on how it has changed in the past.

There are obvious costs involved in using an evolutionary perspective on diplomacy. When the focus is on humanity's agency in general, the agency of specific humans is occluded. So are issues of power, and also of meaning. An evolutionary perspective is necessarily functionalist, which easily spells circularity if a causal reading is insisted upon. By the same token, organicism is a dangerous trap. Natural selection is guaranteed by biological factors that do not immediately translate into the social. There is no biological mutational logic in the social. When we speak of social mutations, we are speaking metaphorically. There is no such thing as social natural selection. Social selection processes are to do with factors such as density of habitat, social complexity, competition and cooperation regarding resources. They give rise to social phenomena such as specific forms of signaling and communication. The emergence of language would be a key example. A more recent one would be the emergence of the world wide web. These are stochastic factors, as opposed to natural ones. These are all very good reasons why nobody has really applied an evolutionary 
way of thinking to diplomacy before. I nonetheless think this is an exercise worth the candle because an evolutionary frame gives us a kind of longue durée overview that is not readily available from elsewhere. It is in this spirit, and keeping in mind how evoking evolution may all too easily steer us down an asocial biologistic path, that I nonetheless find it useful to take evolutionary thinking to the case of diplomacy. In terms of beginnings, there is no reason why we should not begin our investigation as early as extant proof of human cooperation allows. The longue durée view allows us to speculate about further evolution of diplomacy from a wider and hence more solid base than if we think more short-term, say in centuries. Here we may already complement dominant approaches within diplomatic studies, which tend to see change in diplomacy as a result of dynamics internal to diplomacy itself (but see Der Derian 1987; Neumann 2011; Bátora and Hynek 2014). Applying an evolutionary perspective to diplomacy is one way to demonstrate how diplomacy grows out of general social and environmental change.

I begin by discussing the general emergence of human cooperation and how it relates to diplomacy. Given the state of our knowledge, this part is necessarily speculative, and so I throw in some notes on method. Part two discusses earlier evolutionary work, or, to be more precise, the earlier work, on diplomacy. Part three tries to move the discussion forward by introducing and applying the idea of evolutionary tippingpoints to the study of diplomacy. Tipping-points are understood here as the moment when long-term selection processes crystallize in diplomatic institutionalization. Let me give an example of concrete procedure. I do not argue that, say, the founders of the League of Nations had no agency, or that questions of culture-specific power were not very important to this process. Far from denying this, I use an evolutionary 
perspective to focus on the long-term preconditions for this tipping-point of multilateral diplomacy. Evolutionary thinking enables a focus on the line to be drawn from early gatherings of tribes in a number of global locations, via Christian church meetings in the mediaeval period and so-called congress meetings by states, to the early stirrings of permanent multilateral diplomacy in nineteenth century institutions such as the Central Commission for the Navigation on the Rhine and the International Telegraph Union. Having introduced the idea of tipping-points, the rest of part three looks for moments when the institutionalization of diplomacy firmed historically, and identity six such tipping-points. In conclusion, I speculate about the emergence of a seventh tipping-point, which challenges the present hierarchy of diplomatic agents.

When the species was young, selection was individual. With increased cooperation, the unit of selection changed from individual to group. I will follow archaeological consensus (Smith 1964; Ridley 1996; Boehm 1999, 2011) and take the increased level of cooperation to follow on from the event of big game hunting, and to see big game hunting as ushering in a political revolution. It is unclear when this revolution started, with estimates being as old as 300.000 (Thieme 2007) or even 500.000 years ago (Wilkins et al. 2012). The result of collaboration was pivotal in evolutionary terms, because it immediately led to a change in the unit of natural selection. Thus, we might add 'natural cooperation' as a third fundamental Principle of evolution beside natural and sexual selection (Nowak 2006: 1563). Evolutionary writers on state building focus on natural and symbolic reciprocal exchange (Service 1975: 60; see also Bowles and Gintis2011), with Ragnar Numelin (1950) being the only writer who has, to my knowledge, addressed the phenomenon of diplomacy systematically. 
When Numelin is building exclusively on evidence culled from hunter-gatherer groups observed by anthropologists, this is because the data available at the time when he was writing, in the 1930s, made it very hard to do anything else. As a result, Numelin was condemned to stop at cataloguing relevant phenomena (as they were evident from the anthropological record) and could not go on to attempt much theorization. He does not look at what the evolutionist Morton Fried (1967, in the context of the change from chiefdoms to states) refers to as 'leaps' of evolution. It seems to me that an attempt to pinpoint candidates for such leaps, tipping points or, to use evolution-speak, punctuated equilibrium effects (Eldredge and Gould [1972] 1985; for a recent critical assessment, see Scott 2007) must be the next logical step in applying evolutionary thinking to the case of diplomacy. ${ }^{2}$

\section{A new approach to the history of diplomacy: Tipping points}

Tipping-points, understood as the culmination of long-term trends, are often institutionalized in the context of attempted learning once the victors (and sometimes the losers, too) to a conflict have had the chance to sit down and ponder what went wrong the last time. Note, however, the contingent character of the social changes that bring on tipping-points. I am not prepared to privilege any one set of factors that determine diplomacy. Social evolution does not work like that. Stuff emerges, becomes problematized and leads to cooperational and conflictual behavior without the organic laws of biology to underpin the process, which therefore remains stochastic. Furthermore, most social stuff preserves pre-tipping point stuff as part of 
the whole picture. The social is like a palimpsest, where older practices shine through amongst the dominant and newest ones. ${ }^{3}$ Specifically, diplomacy may reach a tipping point, and as seen from the time intervals between them, history seems to be speeding up so that we now spend centuries or even decades rather than millennia in reaching a new tipping point. Once the tipping point has been reached, however, previous practices do not simply disappear, but tend to hover. One contemporary example would be how a state like Russia is markedly less involved in multilateral practices than is, say, Germany.

We have already encountered one leap or tipping-point, namely the political revolution brought on by the possibility of big game hunting some 300.000 years ago. Here, the selection process was driven by increased complexity in signaling. While this revolution first and foremost had the effect of increasing the value of in-group cooperation, it also suggested the possibility of cooperation between groups. Such cooperation would take diplomacy to come into being. Let us call the Pleistocene revolution of big-game hunting a proto-diplomatic tipping-point.

Note that 'cooperation' is a positively loaded word, and this occludes the importance of social relations for it to work. Every social scientist is, for example, familiar with Rousseau's fable of the stag hunt, where the point is that if only one of a hunting party spots a hare and breaks rank by killing it, the cooperative scheme to catch a stag will fall apart. The antidote to this is the wielding of social power. To pick an example from the life of contemporary hunters and gatherers once again, in an ethnographic study of the !Kung, Shostak (1976) found that of the hours of quotidian conversation that she had recorded on tape, over one-third was spent on criticising selected good 
hunters for not being cooperative enough, often within their earshot or even to their faces. If all known human settings display the use of power to keep cooperative schemes on the tracks, it is a safe assumption that the same went for the late Pleistocene revolution, and that it was, consequently, power-laden.

This is important, for it should remind us of how cooperative schemes such as diplomacy are shot through with power relations. It is, for example, not the case that diplomacy is the opposite of war (see Barkawi, 2015). It is, rather, the opposite of not talking to the enemy. Diplomacy is attempts by socially designated representatives at handling difference on the group level by means of a cocktail of practices with talk being paramount amongst them. The major importance of the late Pleistocene revolution to diplomacy, then, lies in the way it further institutionalized cooperative schemes as a standard modus operandi of human life in general. It enhanced the social space for action taken on other bases than at spear-point as well as for non-verbal and, in historical perspective, verbal communication of a non-violent but definitely powerladen kind. ${ }^{4}$

Numelin's work suggests a second tipping-point, namely totemism, which may serve as a template for turning living beings who were before considered impossible to talk to into interlocateurs valable by offering a ground on which to cooperate, namely the fact of sharing a common totem. While this is a highly tentative idea, if we fastforward from hunter-gatherer groups to societies about which we have written knowledge, we do see a similar mechanism in operation. In all known early examples of diplomatic practices, kinship appears as a template. The Amarna system, named after the findings of stone tablets documenting correspondence between $1300 \mathrm{BC}$ 
polities such as Egypt, Babylonia, Assyria and the Hittite polity Hatti, a key theme is the ongoing attempts by the other Kings to have the Egyptians acknowledge them as brothers, and not sons. The ancient Greek practice of 'discovering' kin, invariably groups of barbarians so strong that they could not be ignored but had somehow to be dealt with, with the Macedonians being a prime example, brings out the logic (Neumann 2011). Kinship offers a language of categorization within which diplomatic maneuvering may take place. This still goes on within what is, appositely, often diplomatically called the 'family' of nations, i.e. the states system. Similar practices are known from other diplomatic systems, such as the Iroquois League which operated ca. 1300-1750. Given the overwhelming importance of kinship for all political organization, we are on fairly safe ground in assuming that the use of kinship-speak constituted a tipping-point of very old standing. How old, we have no way of knowing. Note that, contrary to the first tipping point, which springs from a material factor, namely that the end of the Pleistocene ice age brought a warmer climate conducive to the emergence of edible megafauna, this tipping point is brought on by social organization itself.

A third tipping-point is suggested by recent archaeological research, and concerns the process of sedentarization. The selection process that drove this was certainly habitat density, which led to increased competition between like units and also to cooperation amongst them. First, consider the emergence of villages. The earliest known cropped up in Anatolia some 7000 years ago, and were not directly tied to agriculture. However, those that emerged in Sumer around 3500 BC were. For our purposes, the key thing to note is that there was more than one. Thus a pattern was initiated where culturally similar but politically distinct entities emerged in the same place. Renfrew 
and Cherry (1986) have called these peer-group polities. These polities interacted on a regular basis, from territorially stable positions. The result was institutionalized patterns of interaction, which we may see as the first embryonic diplomatic patterns. They have been studied first and foremost for their state-building results; Sumerian polities were united under a King already around BC 2900.

The Neolithic period is better understood than earlier periods because it overlapped with human memory in a sufficient degree to leave accounts in early writing, and because it left more material remnants. One example of these are the stone megastructures of what we now call Northern Europe, which have been interpreted as constituting a second variant of this third tipping point. Some of these monuments have been read as representing the graveyards of different polities, gathered in one place, and serving not only as focal points for gatherings of the tribes, but also as material constitutive elements of what we may see as early diplomatic systems. For example, Renfrew (2007) interprets Stonehenge in this way. Noting that there was too much rainfall in Northern Europe for conditions to allow the kind of mud-hut based villages that were in evidence in places like Sumer and further south in Europe, he postulates that the emerging sedentary culture needed a focus, and that 'the great henges would have served as ceremonial centres and perhaps also as pilgrimage centres for their parent communities $[\ldots]$ the end product was the emergence of a coherent larger community where none was before' (Renfrew 2007: 155-6).

If Renfrew is right, then there is a line to be drawn from the constitution of diplomatic relations centred on henges to the further rise of chiefs heading peer-group polities and on to these chiefs vying for supremacy in early state building processes that 
resemble those found in Sumer. Examples include not only British kingdoms, but also Scandinavian ones and their offsprings, such as the Rus', arising around AD 800-1000 (Earle 1997, Neumann 2013b). What we may call the Viking world evolved stable patterns of diplomatic relations in the area stretching from Britain in the West to Rus' in the east, as well as diplomatic contact with dominating polities further south, such as the Byzantine empire.

Byzantium, with its patterned diplomatic relations with surrounding polities, was late to the ball, however, for the large-scale diplomatic relations between culturally distinct polities in evidence here were spearheaded in the area where Sumer was based, the East Mediterranean. Sumer's successor polity, Akkad, had regular diplomatic contacts with other Kingdoms already in the third millennium BC, and eventually became a founder member of the first diplomatic system, the secondmillennium BC Amarna system, consisting of polities such as Babylonia, Egypt and Hatti, whose lingua franca was indeed Akkadian (Cohen and Westbrook 2000). The emergence of this first large-scale diplomatic system clearly constitutes a fourth tipping-point in the evolutionary history of diplomacy, driven by increased social complexity. Note that Greece, which is so often seen as the cradle of Western civilization and of diplomacy both, constitute an example of the third tipping-point, culturally similar peer-group polities interacting, at a time (the fourth century BC) when the fourth tipping point had been in evidence elsewhere for 1500 years or so. Where diplomacy is concerned, the Greek poleis are an example of evolutionary reemergence; it is not a tipping-point. The same would be the case for the already mentioned Iroquois diplomatic system in Turtle Island (ca. AD 1300-1750; see Neumann 2011). 
A fifth tipping-point was reached as social interaction between large-scale polities intensified, and the need for more permanent exchanges than that afforded by messengers made itself felt. Once again, increased social complexity and more advanced signaling characterize the process. The answer was to base exchanges not only on messengers, but also on letting people who were sedentary within one polity handle relations with other polities on a running basis. There are early examples on this, for example traders within the Amarna system, the institution of the proximos in ancient Greece, which involved citizens of one polis who were particularly close to some other Greek polis, and also in Africa. From the fourth century AD, different branches of Christendom evolved the institution of apocrisiarii, whereby some representative of the Catholic Church was resident in Byzantium. The first permanent, reciprocal and so fully-fledged example of this institution, which came to be known precisely as permanent diplomacy, hails from the fourteenth-century Italian city-state system (Neumann 2011). After centuries of wrangling about reciprocity, permanent diplomacy went on to become a global phenomenon in the twentieth century.

By then, a sixth tipping-point was already well in the making, driven by increased social complexity but also by technological innovation in the area of communication, particularly in infrastructure. We know it as internationalism. Its pre-history reached back to the institution of the gathering of the tribes, which we touched on already in our discussion of Stonehenge. A more elaborate form of this institution took the form of the irregular church meetings of the Catholic Church from the fourth century onwards and the kurultais that were called to choose successor rulers in the TurkoMongol tradition of Eurasian steppe politics. The emergence of 'international' (that is, 
with states as members) organizations such as the Central Commission for the Navigation on the Rhine (1815) and the International Telegraph Union and International Postal Union during the second half of the nineteenth century brought permanence to what was soon to be called multinational diplomacy, just as permanence had been brought to bilateral diplomacy some centuries before. With the founding of the League of Nations in 1919, permanent multilateral diplomacy went global. The work of the thousands of international organizations in evidence today has increased the number of people doing diplomatic work enormously, and has lent to global diplomacy a much, much more socially dense quality than it had only a hundred years ago. Whereas the number of diplomats on the eve of the First World War could be counted in four-digit numbers, diplomats working for the state today are counted in six-digit numbers, and if we add international civil servants, activists in non-governmental organizations, consultants, spin doctors and so on, we probably reach a seven-digit number.

\section{Conclusion}

The evolutionary history of diplomacy may be told by way of identifying six tipping points: the late Pleistocene political revolution some 300.000 years ago; classificatory kinship as a template for regular cooperation (date unknown); regular and ritualized contacts between culturally similar small-scale polities (5.500 years ago); regular and ritualized contacts between culturally different large-scale polities (4.000 years ago); permanent bilateral diplomacy (five centuries ago) and permanent multilateral diplomacy (one century ago).

Extant work on diplomacy tends to discuss change in the institution as a function of developments internal to it. However, diplomacy is embedded in everyday social life. 
One strength of an evolutionary approach is that it can clearly demonstrate this, by directing attention to how diplomacy's social and material environment sets in motion developments which lead to tipping points. So it is with possible future developments; their origins must be sought outside of the institution of diplomacy itself, in diplomacy's environment. There is little doubt that candidate number one is the shift away from a world centred around the states system, toward a globalized world, with globalization referring to the increase in global social density and the condensation of spatiality and temporality. Like its forerunner, internationalism, the selection process is characterized by technological innovation in the area of communication, particularly software infrastructure and so-called social media. The explosion in public diplomacy is a key development here. As a result, an unprecedented degree, what happens in one local site is imbricated in developments elsewhere. As flows of people, ideas, trade and services increase rapidly, the importance of boundaries between states changes. State discreteness is challenged, and with it, state agency. To put it differently, the environment for state action changes rapidly, and this cannot but have repercussions on a diplomacy whose major agents are state, for it puts the centrality of the state system to global politics in question, and raises the question of how states change as they try to optimize their role in the new environment.

There are two conventional answers to this question. ${ }^{5}$ The first is that other, non-state agents threaten to overtake states. The second is that states keep on as before, with the one proviso that they delegate functions to other agents and become the principal agent of those other agents. In an evolutionary perspective, the first answer is wanting, for there is little or no evidence that the new environment fits other agents better than it does states (Spruyt 1994a). States are certainly changing, but adaptation 
is not disappearance. The second answer also comes up short, for in an evolutionary perspective, state delegation means reshuffling, and reshuffling has recursive effects that will change the states that delegate. We must somehow account for all that, and I think the best way to do it is to grant the point that new agents become more important, and also the point that states seem to be able to harness most of the activity of these new agents for their own uses. What is about to happen, then, is that the former hierarchy of agents, with states firmly on top and with various kinds of nonstate agents layered below them, is being condensed and hybridized. States retain their key status, but they become less like territorially bound entities that serve as containers for social life, and more like central nodes in networks of agents.

This has immediate repercussions for diplomacy, for it means that state agents may be found in other kinds of organizations. The posting of British and French diplomats to posts in ostensibly non-state development organizations dates back more than a decade. Non-governmental presence in Canadian and Norwegian negotiation teams emerged in the 1990s. Less formal use of seemingly free agents by key diplomatic agents is as old as institutionalized diplomacy itself. It also means that other organizations try to copy diplomatic organizational models for how to operate 'in the field'. Military attachés have done this for centuries. The 'expat' divisions of transnational companies are usually organized along lines first laid out by diplomats, and former diplomats are often employed by them. Non-governmental organizations specializing in development aid, humanitarian relief, peace and reconciliation work and so on similarly organize their expatriates on models lifted from diplomatic services. It is not just the diplomatic system of states that is evolving, it is the social context that is evolving, taking diplomacy with it. Non-state actors are taking on 
diplomatic type roles. The new tipping- point, which is already well advanced, is what we may call the hybridization of diplomacy; state and non-state actors become more similar, they face similar cooperation problems as did other constellations of diplomatic agents before them, and they partake of shifting alliances. The central role of states will probably not fade, but states will increasingly have to work with and through other kinds of agents, rather than on them, as they usually did before. As always when a new tipping point arises in social spheres, this is not totally new. In a social setting, as the example of how right-hand driving conquered Europe bore out, a tipping-point is something that is reached gradually. Britain and most of Asia still drives on the left hand of the road. A tipping-point is not something that does away with previous practices overnight. When looking back at the emergence of diplomacy with a hunch that the next tipping-point is hybridization of agents, one spots plenty of forebodings. Neither - and this is where the digital example of left-hand vs. righthand driving no longer more complex social stuff such as diplomacy—do new practices totally eradicate old ones.

We seem to be gathering momentum for a new tipping point, where hybridized diplomacy becomes the new norm. Exactly when a tipping point has been reached, wcan only be known in retrospect. Furthermore, and to repeat a point, the occurrence of a new tipping point does not mean that a number of time-hallowed diplomatic practices will automatically disappear. Punishment is famously costly (war) or ineffectual (sanctions, embargoes), as are rewards (development aid, intention agreements), but the logics are broadly the same as those we may identify for cooperation generally. As for the mechanisms concerned, while diplomacy is ubiquitous throughout human history, reciprocity was key to the formation of 
diplomatic systems such as the Sumer system, the Amarna system, the Iroquois system and the European post-Renaissance system. While scattered cases of diplomacy based on symmetrical reciprocity may be observed elsewhere-SverdrupThygeson (2011) looks at the Chinese case and highlights relations with the Liao in the ninth century and the relations with the Russian empire in the seventeenth, and we could add relations with the Hsiung-nu during the last two centuries before our erathey were not permanent enough to take root. While power asymmetries between Europe and the rest of the world over the last two hundred years are of course absolutely central to understand how European practices became the major source for today's global diplomacy, and examples of how European states drew on power asymmetries to ram through diplomatic rules and treaties are rife, the fact that there already existed a European system based on reciprocity that could be exported globally is also a factor in understanding why it is that other origins have left so few marks on current diplomatic practices (Neumann 2012). A particularly illuminating example is the emergence of permanent representation, where powers such as the Ottoman Empire and China failed to reciprocate by not sending permanent representatives to European powers exactly because this would be a sign of accepting these powers on an equal basis, and so give up on the claim to superiority. As late as twenty years ago, the importance of reciprocity was perhaps most easily observed in the quid pro quo practices of declaring foreign diplomats as personae non grata. Interestingly, since then, there has been a movement away from host countries expelling people, towards a practice where states which expect that the host country are about to take such action voluntarily send the diplomats involved back. In our perspective, such anticipation must be interpreted as yet another victory for cooperation, because it forestalls overt quarrels. 
The factors that create an institution are not necessarily the same as those that uphold it, however. When discussing the future of diplomacy, the relevant thing is not how trust, communication, the ability to determine people's reputation as trustworthy partners, and the perception that the interaction is fair played out in previous centuries, but rather what is the current state of play. Trust and communication are fairly well established. So, as is evident in the existence of an increasingly thick diplomatic culture, is we-feeling. To give but one example, Wille (2013) recently reported that, when asked why he taught diplomatic skills to young Eastern European diplomats that his own country would one day meet in negotiations, their German instructor answered that the higher the common understanding of the rules of the game, the easier the negotiations, and the higher the chance of getting to yes.

At certain historical junctures, diplomacy has been singled out as the root cause of the world's ills. After the First World War, many liberals pointed to secret diplomacy as the major cause for why war broke out. Revolutionary regimes from France via Russia to Iran have blamed diplomacy for why the world order was like it was. Today, we sometimes hear that diplomacy is not so much evil as it is out of touch with key issues that call for more cooperation. I would argue that all these views are mistaken. As I have tried to demonstrate here, diplomacy is a hard-won triumph of the species. In an evolutionary perspective, it is the recursive result, and not the cause, of cooperation between human polities. It has intensified from small-scale to large-scale, from intermittent to permanent, from bilateral to multilateral. Viewed closer up, all kinds of specific changes in diplomatic practices are in the making, with the 
articulation of sundry non-state agents to state agents being perhaps foremost amongst them. A new tipping-point is on its way. Since evolutionary explanations are by definition functionalist and long-term, it makes little sense to apply an evolutionary perspective to small-scale changes. Suffice it to say, therefore, that it would be highly detrimental for the future of human cooperation to throw away the hard-won institution of diplomacy, for it would do no more than face us with the task of building something similar all over again. Diplomacy will change as a result over change in the overall social fabric in which it is embedded, but it will not disappear.

\section{Notes:}

${ }^{1}$ The funding for this article was provided by the Norwegian Research Council under the project 'Evaluating Power Political Repertoires (EPOS)', project no. 250419. 2 Mention should be made here of Hendrik Spruyt's (1994a; 1994b: 188) work on the states system, which did bring the idea of punctuated equilibria to the study of IR. However, as Bátora and Hynek (2014) argue, 'since diplomacy is not seen [by Spruyt] as a specific institution, but rather as a centralized gatekeeping tool of newly formed political units, it cannot be linked to the discussion of social evolutionary change per se. This can be seen when Spruyt tackles adaptation to environmental demands in the context of evolving units in the international system but never in the context of diplomacy. Finnemore and Sikkink (1998) talk about 'turning points' in the life cycle of a norm when enough states join its institutionalized form; this is an agency-focused use which is very different from an evolutionary take.

3 Sometimes, only a metaphorical echo remains. Where humans are concerned, the expression prick up your ears would be an example of this. 
4 The use of 'verbal' here may not be correct, for we do not know when language emerged, or even if it emerged suddenly or gradually. Most guesses place the event in the $\mathrm{BC} 100.000-70.000$ range. One unresolved tension is the relationship between the actuality of big-game hunting, which demands advanced signaling, and the emergence of language.

5 This paragraph summarizes Neumann and Sending 2010. 


\section{References}

Barkawi, T. (2015). 'Diplomacy, War and World Politics' in Pouliot, V., Sending, O.

J. and Neumann, I. B. (eds.) The Future of Diplomacy Cambridge: Cambridge

University Press, 55-79

Bátora, J. and Hynek, N. (2014). Fringe Players and the Diplomatic Order: Towards a 'New' Heteronomy?, London: Palgrave.

Bowles, S. and Gintis, H. (2011). A Cooperative Species: Human Reciprocity and Its Evolution, Princeton, NJ: Princeton University Press.

Boehm, C. (2011). Moral Origins: Social Selection and the Evolution of Virtue, Altruism, and Shame, New York: Basic.

Carman, J. and Harding, A. (1999) Ancient Warfare: Archaeological Perspectives, Stroud: Sutton.

Boehm, C. (1999). 'The Natural Selection of Altruistic Traits', Human Nature, 10 (3): 205-52.

Cohen, R. and Westbrook, R. (2000, eds.). Amarna Diplomacy: The Beginnings of International Relations, Baltimore, MD: Johns Hopkins University Press.

Darwin, C. [1873] (1998). The Descent of Man, Amherst, MA: Prometheus.

Der Derian, J. (1987). On Diplomacy. A Genealogy of Western Estrangement, Oxford: Blackwell.

Earle, T. K. (1997). How Chiefs Come to Power: The Political Economy in Prehistory, Stanford, CA: Stanford University Press. 
Eldredge, N. and Gould, S. J. [1972] (1985). 'Punctuated Equilibria: An Alternative to Phyletic Gradualism', in Eldredge, N. (eds.) Time Frames, Princeton: Princeton Univ. Press, 193-223.

Finnemore, M. and Sikkink, K. (1998). 'International Norm Dynamics and Political Change', International Organization, 52 (4): 887-917.

Fried, M. (1967) The Evolution of Political Society New York, NY: Random House.

Fry, D. P. (2007) Beyond War: The Human Potential for Peace Oxford: Oxford University Press.

Hamilton, K. and Langhorne, R. [1995] (2011). The Practice of Diplomacy: Its Evolution, Theory and Administration, second edition, London: Routledge.

Kurizaki, S. (2011). 'A Natural History of Diplomacy', chapter three of a book manuscript titled When Diplomacy Works, last accesed on June 15, 2015 at http://people.tamu.edu/ kurizaki/b3.pdf.

Marlowe, F. W. (2005). 'Hunter-Gatherers and Human Evolution', Evolutionary Anthropology, 14 (2): 54-67.

Munn-Rankin, J. M. (1956). 'Diplomacy in Western Asia in the Early Second Millennium BC', Iraq, 18 (1): 68-110.

Maynard Smith, J. (1964). 'Group Selection and Kin Selection', Nature, 201 (4924): $1145-7$

Neumann, I. B. (2013a). Diplomatic Sites: A Critical Enquiry, London: Hurst.

Neumann, I. B. (2013b). 'Claiming The Early State For The Relational Turn: The Case of Rus' (ca. 800-1100)', in Tickner, A. B. and Blaney, D. L. (eds.) Claiming The International, London: Routledge, 78-97. 
Neumann, I. B. (2012). 'Euro-Centric Diplomacy: Challenging but Manageable', European Journal of International Relations, 18 (2): 299-321.

Neumann, I. B. (2011). At Home with the Diplomats: Inside a European Ministry of Foreign Affairs, Ithaca, NY: Cornell University Press.

Neumann, I. B. and O. J. Sending (2010) Governing the Global Polity: Practice, Rationality, Mentality Ann Arbor, MI: University of Michigan Press.

Nicolson, H. [1939] (1963). Diplomacy, third edition, London: Oxford University Press.

Nowak, M. (2006). 'Five Rules for the Evolution of Cooperation', Science, 314 (5805): 1560-3.

Numelin, R. (1950). The Beginnings of Diplomacy: A Sociological Study of Intertribal and International Relations, London: Oxford University Press.

Renfrew, Colin (2007) Prehistory: The Making of the Human Mind London:

Weidenfeld \& Nicolson.

Renfrew, Colin \& John Cherry (eds.) (1986) Peer Polity Interaction and SocioPolitical Change Cambridge: Cambridge University Press.

Ridley, M. (1996). The Origins of Virtue. Human Instincts and the Evolution of Cooperation, New York: Viking.

Scott, H. (2007). 'Stephen Jay Gould and the Rhetoric of Evolutionary Theory', Rhetoric Review, 26 (2): 120-41.

Scott, J. C. (2013). 'Crops, Towns, Government' London Review of Books, 35 (22): $13-5$.

Scott, J. C. (2009). The Art of Not Being Governed: An Anarchist History of Upland Southeast Asia, New Haven, CN: Yale University Press. 
Service, E. R. (1975). Origins of the State and Civilization: The Process of Cultural Evolution, New York: Norton.

Shostak, M. (1976). Nisa: The Life and Words of a !Kung Woman, Cambridge, MA: Harvard University Press.

Spruyt, H. (1994a). 'Institutional Selection in International Relations: State Anarchy as Order', International Organization, 48 (4): 527-57.

Spruyt, H. (1994b). The Sovereign State and Its Competitors, Princeton: Princeton University Press.

Sverdrup-Thygeson, B. (2011). 'A Neighbourless Empire? The Forgotten Diplomatic Tradition of Imperial China', The Hague Journal of Diplomacy, 7 (3): 1-23.

Thieme, H. (ed.) (2007) Die Schöninger Speere - Mensch und Jagd vor 400.000 Jahren, Stuttgart: Konrad Theiss.

Watson, A. (1992). The Evolution of International Society: A Comparative, Historical Analysis, London: Routledge.

Wilkins, J., Schoville, B. J., Brown, K. S., and Chazan, M. (2012). 'Evidence for Early Hafted Hunting Technology', Science, 338 (6109): 942-6. doi:

10.1126/science. 12276 .

Wille, T. (2013). The Diplomatisation of Kosovo. Paper read at the London School of Economics, 2 December 2013.

Young, H. P. (1998). Individual Strategy and Social Structure. An Evolutionary Theory of Institutions, Princeton, NJ: Princeton University Press. 